\title{
INOCULAÇÃO COM RIZÓBIO ASSOCIADO AO MANEJO DA ADUBAÇÃO NITROGENADA EM FEIJÃO COMUM
}

Roberta Vasconcelos Ramires ${ }^{1}$, Sebastião Ferreira De Lima ${ }^{2}$, Cátia Aparecida Simon ${ }^{3}$, Lucymara Merquides Contardi ${ }^{2}$, Rita de Cássia Félix Alvarez ${ }^{2}$, Marivaine da Silva Brasil ${ }^{4}$

${ }^{1}$ Universidade Federal dos Vales de Jequitinhonha e Mucuri, Diamantina, MG. ${ }^{2}$ Universidade Federal de Mato Grosso do Sul - UFMS, Campus Chapadão do Sul, MS. ${ }^{3}$ Universidade de São Paulo - USP, ESALQ, Piracicaba, SP. ${ }^{4}$ Universidade Federal de Mato Grosso do Sul, Campus do Pantanal, Corumbá, MS. E-mail: robertavasconcelos22@hotmail.com

\section{RESUMO}

O feijoeiro comum, embora seja cultivado em todo território brasileiro, apresenta baixa produtividade, sendo uma cultura de ciclo curto exigente em fertilidade, principalmente em fósforo e nitrogênio. 0 objetivo deste trabalho foi avaliar a resposta de duas cultivares de feijão comum à inoculação com Rhizobium tropici em associação ao manejo de nitrogênio. Foram instalados dois experimentos, um com o feijão Jalo precoce e outro com o feijão BRSMG Majestoso, em delineamento experimental em blocos casualizados, em esquema fatorial $2 \times 4$, com quatro repetições. Os tratamentos foram constituídos pela inoculação ou não de $R$. tropici nas sementes e quatro formas de adubação na semeadura/cobertura (0/0, 20/0, 0/120 e 20/100 kg ha ${ }^{-1} \mathrm{~N}$ ). A aplicação de $\mathrm{N}$ afeta a produção e a massa seca de nódulos no feijão Jalo precoce e Majestoso. A inoculação propicia maiores teores de $\mathrm{N}$ foliar e de grãos para o feijão Jalo precoce. A aplicação de $\mathrm{N}$ em semeadura e ou em cobertura resulta em maiores teores de $\mathrm{N}$ foliar e de grãos para o feijão Majestoso. Obtêm-se as maiores produtividades de grãos para o feijão Jalo precoce nas maiores doses de $\mathrm{N}$ sem inoculação e com $20 \mathrm{~kg} \mathrm{ha}^{-1} \mathrm{~N}$ na semeadura quando inoculado. A presença de rizóbios nativos pode ter favorecido o feijão majestoso que obteve as maiores produtividades de grãos sem o uso de $\mathrm{N}$ e com $20 \mathrm{~kg}$ na semeadura.

Palavras-chave: adubação nitrogenada; fixação biológica de $\mathrm{N}_{2}$; Phaseolus vulgaris.

\section{RIZOBIUM INOCULATION ASSOCIATED WITH NITROGEN FERTILIZER MANAGEMENT IN COMMON BEAN}

\begin{abstract}
The common bean, although it is cultivated in all Brazilian territory, presents low productivity, being a culture of short cycle demanding in fertility, mainly in phosphorus and nitrogen. The objective of this work was to evaluate the response of two common bean cultivars to Rhizobium tropici inoculation in association with nitrogen management. Two experiments were carried out, one with Jalo precocious beans and another with BRSMG Majestic beans, in a randomized complete block design, in a $2 \times 4$ factorial scheme, with four replications. The treatments were constituted by the inoculation or not of $R$. tropici in the seeds and four forms of fertilization in the sowing / covering (0/0, 20/0, 0/120 and 20/100 kg ha ${ }^{-1} \mathrm{~N}$ ). The application of $\mathrm{N}$ affects the production and the dry mass of nodules in the Jalo precocious and Majestic beans. The inoculation provides higher levels of $\mathrm{N}$ foliar and grains for early Jalo beans. The application of $\mathrm{N}$ in sowing and / or cover yields higher levels of $\mathrm{N}$ foliar and of grains for Majestic beans. The highest grain yields were obtained for early Jalo beans at the highest $\mathrm{N}$ doses without inoculation and at $20 \mathrm{~kg} \mathrm{ha}^{-1} \mathrm{~N}$ at sowing when inoculated. The presence of native rhizobium may have favored the majestic beans that obtained the highest yields of grains without the use of $\mathrm{N}$ and with $20 \mathrm{~kg}$ at sowing.

Keywords: nitrogen fertilization; biological fixation of $\mathrm{N}_{2}$; Phaseolus vulgaris.
\end{abstract}

\section{INTRODUÇÃO}

Mesmo possuindo restrições de produtividade pela alta exigência em fósforo e nitrogênio e o custo elevado onerando a produção, o feijoeiro comum (Phaseolus vulgaris L.) tem elevada relevância socioeconômica para o 
Brasil (RICHETTI et al., 2012; KANEKO et al., 2010; HUNGRIA et al., 2001). De acordo com a Conab (2018) em dados disponibilizados para janeiro/2018 até o momento houve redução em área cultivada com feijão, com produção inferior a 100 mil toneladas quando comparada a colheita do ano anterior, sendo esta concentrada na região do Sul do Brasil.

Ainda assim para que o cultivo do feijoeiro possa ser rentável ao produtor e suas sementes acessíveis a toda população, é preciso desenvolver tecnologias de baixo custo, capazes de melhorar os níveis de produtividade dos agricultores (KANEKO et al., 2010). Dentre estas tecnologias, a fixação biológica de nitrogênio (FBN) pode ser uma alternativa para a redução do uso dos adubos nitrogenados, desde que a simbiose com rizóbios supra o $\mathrm{N}$ necessário ao crescimento e desenvolvimento da planta (FONSECA et al., 2013).

A FBN representa a forma mais importante de fixar o nitrogênio atmosférico $\left(\mathrm{N}_{2}\right)$ em amônio, este é o ponto-chave do ingresso do $\mathrm{N}$ molecular no ciclo biogeoquímico desse elemento (TAIZ; ZEIGER, 2017). O rizóbio, neste sistema de simbiose, utiliza os carboidratos provenientes da fotossíntese da planta hospedeira para sua manutenção e promove o processo de FBN, enquanto a planta se beneficia do nitrogênio fixado pela bactéria (STRALIOTTO, 2002).

Pela associação do feijoeiro com bactérias do grupo dos rizóbios, principalmente Rhizobium tropici, é possível substituir quase toda a adubação nitrogenada necessária durante seu desenvolvimento, reduzindo assim, os custos de produção (GRANGE et al., 2007) bem como impactos ambientais. No entanto, a presença ou ausência de nitrogênio no solo ainda pode afetar esta simbiose (VIEIRA et al., 2005). Assim, quando em excesso o nitrogênio pode levar a diminuição da eficiência simbiótica, mas quando aplicado em pequenas quantidades na semeadura, permite maior crescimento de nódulos e consequentemente uma maior FBN, entretanto, se for verificado um teor muito baixo desse elemento no solo, a atividade simbiótica será limitada (HUNGRIA et al., 2003). Foi verificado que a aplicação de $20 \mathrm{~kg} \mathrm{~N} \mathrm{ha}^{-1}$ junto com a inoculação, não prejudica a nodulação, podendo ainda propiciar maior massa seca da parte aérea e maior produtividade de grãos (BARROS et al., 2013)
Mercante et al. (2006) relataram que o uso de inoculante contendo as estirpes de Rhizobium tropici CIAT 899 (= SEMIA 4077) e PRF 81 (= SEMIA 4080) promoveu aumentos significativos na nodulação e no rendimento de grãos das cultivares de feijoeiro (BRS Pontal, BRS Requinte, BRS Vereda e BRS Timbó), mesmo em solos com populações elevadas de rizóbios nativos. Estes autores observaram ainda que, as produtividades obtidas com a inoculação de rizóbios selecionados em feijoeiro mostraram-se superiores àquelas correspondentes aos tratamentos com aplicação de doses de até $80 \mathrm{~kg}$ $\mathrm{ha}^{-1}$ de $\mathrm{N}$, demonstrando a possibilidade de obtenção de incrementos significativos nos rendimentos médios desta cultura, a baixos custos econômicos e ambientais.

O estudo da interação entre o nitrogênio aplicado tanto na semeadura como em cobertura e a inoculação com rizóbios no feijoeiro poderá contribuir para o aumento da eficiência no uso de nutrientes e na produtividade de grãos, além da redução nos custos de produção e nos impactos ambientais, decorrentes dos efeitos deletérios do excesso desse mineral no ambiente. Desta forma, o objetivo deste trabalho foi avaliar a resposta de duas cultivares de feijoeiro comum à inoculação com $R$. tropici em associação ao manejo da adubação nitrogenada.

\section{MATERIAL E MÉTODOS}

O estudo foi realizado na área experimental da Universidade Federal de Mato Grosso do Sul, Campus de Chapadão do Sul/MS (1846'17,8'S e 5237'27,7'W, com altitude de $813 \mathrm{~m})$. O solo da área experimental foi classificado como Latossolo Vermelho distrófico, de textura argilosa, apresentando as seguintes características químicas: $\mathrm{pH}\left(\mathrm{CaCl}_{2}\right)$ de 4,7; 11,6 $\mathrm{mg} \mathrm{dm}{ }^{-3}$ de fósforo; $0,26 \mathrm{cmol}_{\mathrm{c}} / \mathrm{dm}^{-3}$ de potássio, determinado pelo método do extrator Mehlich $^{-1}$; 2,3 e 0,5 $\mathrm{cmol}_{\mathrm{c}} / \mathrm{dm}^{-3}$ de cálcio e magnésio, respectivamente, determinados pelo método do extrator $\mathrm{KCl} 1 \mathrm{~N} ; 8,4 \mathrm{cmol}_{\mathrm{c}} / \mathrm{dm}^{-3}$ de capacidade de troca de cátions (CTC); $36,6 \%$ de saturação por bases (V\%) e $29,5 \mathrm{~g} \mathrm{dm}^{-3}$ de matéria orgânica (M.O.). Segundo a classificação climática de Köppen, o clima predominante da região é do tipo tropical úmido (Aw), com estação chuvosa no verão e seca no inverno e precipitação média anual de $1.850 \mathrm{~mm}$.

Foram estabelecidos dois experimentos, conduzidos no período de safrinha e instalados em campo sob plantio convencional em 
04/03/2013, um com a cultivar Jalo precoce, com ciclo de 77 dias e outro com a cultivar BRSMG Majestoso, com ciclo normal de 90 dias. Cada experimento foi conduzido em esquema fatorial 2 $x 4$, distribuídos em blocos ao acaso com quatro repetições, totalizando 32 parcelas. Os tratamentos foram constituídos pela inoculação ou não das sementes com Rhizobium tropici, utilizando-se $500 \mathrm{~g}$ do inoculante turfoso contendo a estirpe SEMIA 4080, por $50 \mathrm{~kg}$ de sementes e quatro formas de aplicação de nitrogênio (semeadura e cobertura). As formas de adubação nitrogenada foram constituídas por quatro combinações: a) sem aplicação de $\mathrm{N}(0 / 0)$; b) $20 \mathrm{~kg} \mathrm{ha}^{-1} \mathrm{~N}$ aplicados na semeadura e sem aplicação na cobertura (20/0); c) sem aplicação de $\mathrm{N}$ na semeadura e $120 \mathrm{~kg} \mathrm{ha}^{-1} \mathrm{~N}$ em cobertura $(0 / 120)$ e d) $20 \mathrm{~kg} \mathrm{ha}^{-1} \mathrm{~N}$ na semeadura e $100 \mathrm{~kg}$ $\mathrm{ha}^{-1} \mathrm{~N}$ em cobertura (20/100), seguindo as recomendações de Sousa e Lobato (2004), considerando a produtividade de $5 \mathrm{t} \mathrm{ha}^{-1}$. A fonte de nitrogênio utilizada tanto na semeadura como em cobertura foi a ureia ( $45 \%$ de N). A aplicação nitrogenada em cobertura ocorreu em dose única, no início do estádio fenológico V4, caracterizado pela presença da terceira folha trifoliolada, completamente aberta em $50 \%$ das plantas.

Cada unidade experimental foi formada por cinco linhas de $5 \mathrm{~m}$, espaçadas de $0,45 \mathrm{~m}$ entre linhas. Como área útil foram consideradas as três fileiras centrais, sendo que uma das fileiras foi utilizada para as coletas destrutivas e as duas restantes foram utilizadas para a determinação da produtividade de grãos. O controle de plantas daninhas foi realizado na fase inicial de cultivo com a aplicação do herbicida Fomesafen+Fluazifop-p-butyl na dose de $188 \mathrm{~g}+$ $188 \mathrm{~g}$ do i.a ha ${ }^{-1}$. Nos tratamentos com inoculação de $R$. tropici, a mistura do inoculante às sementes foi realizada à sombra, previamente à semeadura.

Por ocasião do florescimento pleno foram coletados os sistemas radiculares de cinco plantas por unidade experimental, em uma das três linhas da área útil. As raízes foram lavadas em água corrente e posteriormente, foi determinado o número de nódulos, mediante contagem, e a massa de matéria seca de nódulos, após secagem do material em estufa com circulação forçada de ar a $65^{\circ} \mathrm{C}$ e pesagem.

Para a determinação de $\mathrm{N}$, foi coletada a terceira folha com pecíolo em 10 plantas por unidade experimental (AMBROSANO et al., 1996) e em seguida, foram secadas em estufa com circulação forçada de ar a $65^{\circ} \mathrm{C}$ até atingir massa constante e posteriormente moídas em moinho do tipo Willey para digestão sulfúrica, conforme metodologia Kjeldahl modificada (GALVANI; GAERTNER 2006).

A matéria seca da parte aérea foi determinada em 10 plantas por unidade experimental, obtidas em pleno florescimento da cultura, na mesma linha de coleta de raízes, por tratar-se da linha de coletas destrutivas. As plantas foram acondicionadas em sacos de papel, secas em estufa com circulação forçada de ar a $65{ }^{\circ} \mathrm{C}$, até atingir massa constante e pesada em balança de precisão.

A produtividade de grãos foi obtida a partir da trilha das plantas em 2 linhas centrais de $5 \mathrm{~m}$ na área útil de cada parcela. Após a colheita os grãos foram pesados e, assim procedeu-se com o cálculo de produtividade de grãos em $\mathrm{kg}$ $\mathrm{ha}^{-1}$, a $13 \%$ de umidade (base úmida). Para a determinação do $\mathrm{N}$ nos grãos, seguiu-se mesmo procedimento descrito para o $\mathrm{N}$ foliar.

Os resultados foram submetidos à análise de variância, utilizando-se o teste de Tukey a $5 \%$ de probabilidade, para a comparação das médias. Para a contagem e massa seca de nódulos os dados foram transformados em raiz quadrada.

\section{RESULTADOS E DISCUSSÃO}

\section{Experimento com a cultivar Jalo Precoce}

Houve interação entre a inoculação e as formas de adubação nitrogenada para número de nódulos, matéria seca de nódulos, matéria seca da parte aérea e produtividade de grãos e efeito individualizado da inoculação para teor de nitrogênio nas folhas e nos grãos (Tabela 1). 
Tabela 1. Resumo da análise de variância para número de nódulos (NN), massa seca de nódulos (MSN), massa seca da parte aérea (MSPA), produtividade de grãos (PROD), teor de nitrogênio nas folhas (TNF) e teor de nitrogênio nos grãos (TNG) no feijão Jalo precoce cultivado sob adubação nitrogenada e inoculação com Rhizobium tropici em Chapadão do Sul, 2013.

\begin{tabular}{cccccccc}
\hline \multirow{2}{*}{$\begin{array}{c}\text { Fonte de } \\
\text { variação }\end{array}$} & GL & \multicolumn{7}{c}{ QM } \\
\cline { 3 - 8 } & & NN & MSN & MSPA & PROD & TNF & TNG \\
\hline I & 1 & $0,03^{\text {ns }}$ & $0,002^{* *}$ & $75,16^{* *}$ & $23442,4^{\text {ns }}$ & $2,32^{* *}$ & $0,60^{* *}$ \\
AN & 3 & $83,37^{* *}$ & $0,070^{* *}$ & $3,73^{* *}$ & $22210,4^{\text {ns }}$ & $0,73^{\text {ns }}$ & $0,01^{\text {ns }}$ \\
I x AN & 3 & $1,53^{* *}$ & $0,00096^{*}$ & $0,73^{* *}$ & $80948,8^{* *}$ & $0,12^{\text {ns }}$ & $0,13^{\text {ns }}$ \\
Resíduo & 21 & 0,28 & 0,00026 & 0,05 & 7627,2 & 0,52 & 0,05 \\
\hline Média & - & 10,77 & 0,188 & 4,53 & 1696,5 & 5,1 & 3,67 \\
CV\% & - & 5,59 & 8,6 & 5,34 & 5,15 & 14,14 & 6,6 \\
\hline *, ** valores significativos pelo teste F a 5 e $1 \%$ de probabilidade; ${ }^{\text {ns }}$ valores não significativos. I=inoculante; \\
AN=adubação nitrogenada; CV\%=coeficiente de variação.
\end{tabular}

Foi observado que tanto os tratamentos que receberam inoculação quanto aqueles que não receberam apresentaram maior formação de nódulos na ausência da adubação nitrogenada, com valores $78,7 \%$ superiores aos obtidos com os tratamentos que utilizaram nitrogênio. Sem a adubação nitrogenada, a inoculação propiciou uma formação de nódulos $8,7 \%$ acima do que foi obtido sem a inoculação (Tabela 2). De acordo com Cardoso e Andreote (2016) a fixação biológica de nitrogênio em leguminosas pode ser afetada por vários fatores, como as populações bacterianas nativas, a espécie hospedeira, temperatura, umidade, $\mathrm{pH}, \mathrm{a}$ deficiência de nutrientes e metais pesados, e principalmente a disponibilidade de $\mathrm{N}$-mineral, sendo este de grande relevância pois a fixação biológica de nitrogênio ocorre em solos no qual ocorre a deficiência de N-mineral. Segundo estes autores, o excesso de $\mathrm{N}$-mineral nos solos está relacionado a demanda nutricional da planta, no qual altas concentrações de $\mathrm{N}$-mineral podem reduzir o estimulo para a produção de nódulos fixadores de $\mathrm{N}$ em plantas leguminosas, variando a intensidade de nodulação de acordo com a dose $\mathrm{N}$-mineral aplicado nos solos.

O resultado obtido contrasta com os verificados por Barros et al. (2013) que encontraram maior número de nódulos no tratamento inoculado e no tratamento adubado e inoculado com $20 \mathrm{~kg} \mathrm{ha}^{-1} \mathrm{~N}$ na semeadura, inferindo que a aplicação de $20 \mathrm{~kg} \mathrm{ha}^{-1} \mathrm{~N}$ na semeadura, não inibe o processo de nodulação da população de rizóbios inoculados. Também é possível observar que sem a inoculação, o tratamento não adubado apresentou $66 \%$ mais nódulos do que os que receberam nitrogênio, provavelmente devido a presença de estirpes nativas. Dessa forma, a aplicação de $\mathrm{N}$ foi o que mais prejudicou a formação de nódulos. Segundo Vieira et al. (2005), Da Silva et al. (2009) e Kaneko et al. (2010) a ocorrência de nódulos no feijoeiro comum que não recebeu inoculação, indica a presença de estirpes nativas no solo capazes de fixar $\mathrm{N}_{2}$ simbioticamente. 
Tabela 2. Valores médios para número de nódulos (NN), matéria seca de nódulos (MSN), matéria seca da parte aérea (MSPA), teor de $\mathrm{N}$ na folha e no grão e produtividade de grãos em feijão cultivar Jalo Precoce cultivada sob adubação nitrogenada e inoculação com Rhizobium tropici em Chapadão do Sul, 2013.

\begin{tabular}{|c|c|c|c|c|}
\hline \multirow[t]{2}{*}{ Tratamentos } & \multicolumn{4}{|c|}{$\begin{array}{l}\text { Formas de fertilização nitrogenada }\left(\mathrm{kg} \mathrm{ha}^{-1}\right) \\
\text { (Semeadura / Cobertura) }\end{array}$} \\
\hline & $0 / 0$ & $20 / 0$ & $0 / 120$ & $20 / 100$ \\
\hline & \multicolumn{4}{|c|}{ Número de nódulos } \\
\hline Inoculado & $14,93 \mathrm{aA}$ & $8,21 a B$ & $8,16 \mathrm{bB}$ & $6,97 \mathrm{aC}$ \\
\hline \multirow{2}{*}{ Não inoculado } & $13,74 \mathrm{bA}$ & $8,54 a B$ & $9,04 \mathrm{aB}$ & $7,18 \mathrm{aC}$ \\
\hline & \multicolumn{4}{|c|}{ Matéria seca de nódulos (g planta ${ }^{-1}$ ) } \\
\hline Inoculado & $0,32 \mathrm{aA}$ & $0,14 a B$ & $0,14 \mathrm{bB}$ & $0,10 \mathrm{aC}$ \\
\hline \multirow[t]{2}{*}{ Não inoculado } & $0,32 \mathrm{aA}$ & $0,15 \mathrm{aC}$ & $0,19 a B$ & $0,11 \mathrm{aD}$ \\
\hline & \multicolumn{4}{|c|}{ Matéria seca da parte aérea (g planta ${ }^{-1}$ ) } \\
\hline Inoculado & $3,59 \mathrm{bB}$ & $4,61 \mathrm{bA}$ & $3,91 \mathrm{aB}$ & $4,51 \mathrm{bA}$ \\
\hline \multirow[t]{2}{*}{ Não inoculado } & $4,36 \mathrm{aC}$ & $6,18 \mathrm{aA}$ & $4,06 \mathrm{aC}$ & $4,99 \mathrm{bB}$ \\
\hline & \multicolumn{4}{|c|}{ Rendimento de grãos $\left(\mathrm{kg} \mathrm{ha}^{-1}\right)$} \\
\hline Inoculado & 1.659aA & $1.752 \mathrm{aA}$ & $1.637 \mathrm{bA}$ & $1.627 \mathrm{bA}$ \\
\hline \multirow[t]{2}{*}{ Não inoculado } & $1.632 \mathrm{aB}$ & $1.562 \mathrm{bB}$ & $1.822 \mathrm{aA}$ & $1.877 \mathrm{aA}$ \\
\hline & \multicolumn{2}{|c|}{ Conteúdo de $\mathrm{N}$ foliar (\%) } & \multicolumn{2}{|c|}{ Conteúdo de N no grão (\%) } \\
\hline Inoculado & \multicolumn{2}{|c|}{$5,37 a$} & \multicolumn{2}{|c|}{$3,81 a$} \\
\hline Não inoculado & \multicolumn{2}{|c|}{$4,83 b$} & \multicolumn{2}{|c|}{$3,53 b$} \\
\hline
\end{tabular}

Médias seguidas da mesma letra minúscula nas colunas e maiúscula na linha, não diferem entre si pelo teste de tukey a $5 \%$.

A massa da matéria seca de nódulos encontrada nos tratamentos sem uso de $\mathrm{N}$ foi $146 \%$ e $113 \%$ maior que a média dos tratamentos que receberam $\mathrm{N}$, quando inoculados e não inoculados, respectivamente (Tabela 2). Silva et al. (2009) verificaram que a massa da matéria seca e o número de nódulos decresceram linearmente a medida que houve aumento da adubação nitrogenada, enquanto Araújo et al. (2007) observaram que o número e a massa da matéria seca de nódulos por planta foram significativamente maiores nos tratamentos com inoculação, quando comparados a testemunha e aos tratamentos com aplicação de nitrogênio mineral.

A maior massa da matéria seca da parte aérea do feijoeiro foi obtida no tratamento não inoculado e adubado com de $20 \mathrm{~kg} \mathrm{ha}^{-1} \mathrm{~N}$ em semeadura, sendo $34 \%$ superior ao tratamento inoculado (Tabela 2), indicando que pequena dose de $\mathrm{N}$ na semeadura pode favorecer a produção de biomassa, apesar de prejudicar a formação de nódulos. O uso de doses maiores de N (0/120 e 20/120) não foi favorável a produção de biomassa nesse feijoeiro.

O feijoeiro inoculado apresentou maiores teores de nitrogênio nas folhas $(5,37 \%)$ e nos grãos $(3,81 \%)$ comparado ao que não inoculado (Tabela 2). Para os autores Souza et al. (2011) a inoculação de rizóbio nas sementes proporcionaram maior teor de $\mathrm{N}$ na folha do feijoeiro, enquanto Kaneko et al. (2010) não encontraram diferenças para o teor de $\mathrm{N}$ nas folhas de feijoeiro com a inoculação de sementes com R. tropici. Para Araújo et al. (2007), o teor de nitrogênio fixado na planta indica a eficiência da FBN pelas estirpes de $R$. tropici no feijoeiro, demonstrando que a inoculação de sementes tem a mesma capacidade de incorporação de nitrogênio à planta.

Ainda pode-se descrever que a adubação nitrogenada na semeadura no feijoeiro, é indispensável para o bom desenvolvimento e produção de grãos com alta qualidade, podendo incrementar sua produtividade (GOMES JÚNIOR; DE SÁ, (2010), isto porque o N é um elemento essencial e necessário para promover o bom desempenho de grãos, no qual o $\mathrm{N}$ absorvido pelos vegetais se liga a esqueletos carbônicos, produzindo aminoácidos, e resultando em proteínas armazenadas nos tecidos vegetais, sendo que na fase de enchimento de grãos estas reservas são quebradas, translocadas e armazenadas nos próprios grãos, na forma de proteínas e aminoácidos (MARSCHNER, 1995). Possibilitando desta maneira a existência de uma relação positiva entre a adubação nitrogenada e acúmulo de proteínas na semente do feijoeiro, no qual diversos autores descrevem que plantas adubadas com altas doses de $\mathrm{N}$ produziram 
sementes com maior teor de proteínas em relação às plantas adubadas com baixas doses deste nutriente (GOMES JUNIOR et al., 2005; GOMES JÚNIOR; DE SÁ, 2010).

Para os tratamentos com inoculação, não houve diferença entre as formas de adubação nitrogenada (Tabela 2). Um fator importante que pode ter interferido na produtividade de grãos para o tratamento inoculado, refere-se ao uso do fungicida na semente, o que pode ter contribuído para redução da eficiência simbiótica. Figueiredo (2012) concluiu que a produtividade de grãos não foi influenciada pela inoculação das sementes com $R$. tropici estirpe CIAT 899, alegando que a população nativa de rizóbio apresentou performance semelhante à da estirpe inoculada. Da mesma forma, Kaneko et al. (2010) e Souza et al. (2011) não obtiveram efeito da inoculação com $R$. tropici sobre a produtividade de grãos do feijoeiro.

\section{Experimento com a cultivar BRSMG Majestoso}

Houve interação entre a inoculação e as formas de adubação nitrogenada para o número de nódulos, massa da matéria seca de nódulos, massa da matéria seca da parte aérea, teor de $\mathrm{N}$ nas folhas e nos grãos e produtividade de grãos (Tabela 3).

Tabela 3. Resumo da análise de variância para número de nódulos (NN), massa seca de nódulos (MSN), massa seca da parte aérea (MSPA), produtividade de grãos (PROD), teor de nitrogênio nas folhas (TNF) e teor de nitrogênio nos grãos (TNG) no feijão Majestoso cultivado sob adubação nitrogenada e inoculação com Rhizobium tropici em Chapadão do Sul, 2013.

\begin{tabular}{cccccccc}
\hline \multirow{2}{*}{$\begin{array}{c}\text { Fonte de } \\
\text { variação }\end{array}$} & GL & \multicolumn{7}{c}{ QM } \\
\cline { 3 - 8 } & & NN & MSN & MSPA & PROD & TNF & TNG \\
\hline I & 1 & $16,49^{*}$ & $0,06^{* *}$ & $3,20^{* *}$ & $332662,2^{* *}$ & $1,78^{* *}$ & $0,23^{* *}$ \\
AN & 3 & $165,75^{* *}$ & $0,39^{* *}$ & $7,11^{* *}$ & $199372,3^{* *}$ & $0,40^{* *}$ & $1,47^{* *}$ \\
I x AN & 3 & $94,40^{* *}$ & $0,09^{* *}$ & $1,78^{* *}$ & $72034,6^{* *}$ & $0,52^{* *}$ & $0,42^{* *}$ \\
Resíduo & 21 & 2,8 & 0,003 & 0,03 & 4261,48 & 0,01 & 0,05 \\
\hline Média & - & 14,28 & 0,34 & 5,18 & 1314,5 & 3,73 & 4,61 \\
CV\% & - & 11,73 & 16,31 & 6,5 & 4,97 & 3,48 & 5,02 \\
\hline
\end{tabular}

*, ${ }^{\text {** }}$ valores significativos pelo teste $\mathrm{F}$ a 5 e $1 \%$ de probabilidade; ${ }^{\text {ns }}$ valores não significativos. I=inoculante; $\mathrm{AN}=$ adubação nitrogenada; $\mathrm{CV} \%=$ coeficiente de variação.

A cultivar do feijoeiro BRSMG Majestoso inoculado apresentou maior formação de nódulos quando não recebeu adubação nitrogenada. Nessa condição, esse tratamento foi $85,3 \%$ superior à média dos tratamentos que receberam nitrogênio. A aplicação de $20 \mathrm{~kg} \mathrm{ha}^{-1} \mathrm{~N}$ na semeadura interferiu menos na nodulação das raízes do feijoeiro quando comparado à aplicação de doses maiores, entretanto, a combinação de aplicação de $\mathrm{N}$ na semeadura e em cobertura, foi mais danoso à nodulação, do que a aplicação da mesma quantidade final de $\mathrm{N}$ apenas em cobertura (Tabela 4). Segundo Cardoso e Andreote (2016) o desenvolvimento de nódulos é menor quando ocorre a disponibilidade de $\mathrm{N}$ no solo, sendo que a ausência de $\mathrm{N}$ disponível no solo promove um estimulo para produção de nódulos fixadores de nitrogênio. Pelegrin et al. (2009) e Silva et al. (2009) não observaram diferenças entre a inoculação com Rhizobium tropici para formação de nódulos, já com a adubação nitrogenada, nas doses até $120 \mathrm{~kg} \mathrm{ha}^{-1}$ $\mathrm{N}$, houve redução linear na nodulação do feijoeiro.

Para o feijão não inoculado, a aplicação de $20 \mathrm{~kg} \mathrm{ha}^{-1} \mathrm{~N}$ favoreceu a formação de nódulos de rizóbios nativos, ficando esse tratamento $91 \%$ acima das médias dos demais tratamentos, com e sem adubação com N. Esses dados corroboram com Vieira et al. (2005) que também encontraram nódulos em plantas de feijoeiro com inoculação e sem inoculação, indicando a presença de rizóbios nativos no solo. Hungria et al. (2007) relataram que a nodulação das raízes supre as necessidades das plantas, devendo-se evitar altas doses da adubação nitrogenada, devido a inibição na formação dos nódulos e a fixação biológica de nitrogênio. 
Tabela 4. Valores médios para número de nódulos, matéria seca de nódulos (Dados transformados em raiz quadrada), matéria seca da parte aérea, teor de $\mathrm{N}$ nas folhas e grãos e produtividade de grãos de feijãocomum cultivar Majestoso cultivado sob adubação nitrogenada e inoculação com Rhizobium tropici em Chapadão do Sul, 2013.

\begin{tabular}{|c|c|c|c|c|}
\hline \multirow[t]{2}{*}{ Tratamentos } & \multicolumn{4}{|c|}{$\begin{array}{l}\text { Formas de adubação nitrogenada }\left(\mathrm{kg} \mathrm{ha}^{-1}\right) \\
\text { (Semeadura / Cobertura) }\end{array}$} \\
\hline & $0 / 0$ & $20 / 0$ & $0 / 120$ & $20 / 100$ \\
\hline & \multicolumn{4}{|c|}{ Número de nodúlos } \\
\hline Inoculado & $22,90 \mathrm{aA}$ & $15,91 b B$ & $12,33 \mathrm{aC}$ & $8,84 a D$ \\
\hline \multirow{2}{*}{ Não inoculado } & $11,84 \mathrm{bB}$ & $21,09 \mathrm{aA}$ & $12,92 \mathrm{aB}$ & $8,39 \mathrm{aC}$ \\
\hline & \multicolumn{4}{|c|}{ Matéria seca de nódulos (g planta ${ }^{-1}$ ) } \\
\hline Inoculado & $0,73 a A$ & $0,55 a A$ & $0,15 \mathrm{aB}$ & $0,13 a B$ \\
\hline \multirow[t]{2}{*}{ Não inoculado } & $0,33 \mathrm{bAB}$ & $0,52 a A$ & $0,21 a B$ & $0,12 \mathrm{aB}$ \\
\hline & \multicolumn{4}{|c|}{ Matéria seca da parte aérea (g planta ${ }^{-1}$ ) } \\
\hline Inoculado & $4,22 \mathrm{aC}$ & $4,90 \mathrm{bB}$ & $4,91 b B$ & $5,41 b A$ \\
\hline \multirow[t]{2}{*}{ Não inoculado } & $3,48 \mathrm{bC}$ & $6,04 a \mathrm{~B}$ & $5,69 \mathrm{aB}$ & $6,76 a A$ \\
\hline & \multicolumn{4}{|c|}{ Teor de N foliar (\%) } \\
\hline Inoculado & $3,08 \mathrm{bC}$ & $3,20 b C$ & $3,67 b B$ & $4,04 a A$ \\
\hline \multirow[t]{2}{*}{ Não inoculado } & $3,88 \mathrm{aB}$ & $4,01 \mathrm{aAB}$ & $4,21 \mathrm{aA}$ & $3,77 \mathrm{bB}$ \\
\hline & \multicolumn{4}{|c|}{ Teor de N nos grãos (\%) } \\
\hline Inoculado & $4,20 \mathrm{aBC}$ & $3,96 b c$ & $4,63 \mathrm{bB}$ & $5,32 \mathrm{aA}$ \\
\hline \multirow[t]{2}{*}{ Não inoculado } & $4,29 \mathrm{aC}$ & $4,56 a \mathrm{aBC}$ & $5,08 \mathrm{aA}$ & $4,88 \mathrm{bAB}$ \\
\hline & \multicolumn{4}{|c|}{ Rendimento de grãos $\left(\mathrm{kg} \mathrm{ha}^{-1}\right)$} \\
\hline Inoculado & $1.219 \mathrm{bA}$ & $1.300 \mathrm{bA}$ & $1.275 \mathrm{aA}$ & $1.054 \mathrm{bB}$ \\
\hline Não inoculado & $1.670 \mathrm{aA}$ & $1.548 \mathrm{aA}$ & $1.295 \mathrm{aB}$ & $1.151 \mathrm{aC}$ \\
\hline
\end{tabular}

Médias seguidas da mesma letra minúscula nas colunas e maiúscula na linha, não diferem entre si pelo teste de tukey a $5 \%$.

A maior massa da matéria seca de nódulos foi observada para o feijoeiro inoculado, sem a aplicação de $\mathrm{N}$, embora não tenha diferido do tratamento com a aplicação de $20 \mathrm{~kg} \mathrm{ha}^{-1} \mathrm{~N}$ em semeadura (Tabela 4), diferindo de Souza et al. (2011) que verificaram que a inoculação com rizóbio não interferiu no número e na massa seca de nódulos.

A aplicação de $20 \mathrm{~kg} \mathrm{ha}^{-1} \mathrm{~N}$ na semeadura e $100 \mathrm{~kg} \mathrm{ha}^{-1} \mathrm{em}$ cobertura proporcionou maior massa seca da parte aérea para o feijoeiro com e sem inoculação. Sem o uso de $N$, o feijão inoculado produziu $21,3 \%$ mais massa de matéria seca da parte aérea que o feijão não inoculado, mas com a aplicação de nitrogênio, o feijão sem inoculação foi superior na produção de massa seca da parte aérea, comparado ao feijão inoculado (Tabela 4).

Para o teor de $\mathrm{N}$ foliar, o tratamento que recebeu $20 \mathrm{~kg} \mathrm{ha}^{-1} \mathrm{~N}$ na semeadura e $100 \mathrm{~kg} \mathrm{ha}^{-1}$ $\mathrm{N}$ em cobertura foi superior aos demais tratamentos, para o feijoeiro inoculado (Tabela 4). Estas aplicações de $\mathrm{N}$ foram as únicas ocasiões em que o feijoeiro inoculado superou o teor de $\mathrm{N}$ do feijoeiro não inoculado, com 7,2\% de teor de $\mathrm{N}$ foliar, diferindo de Silva et al. (2009) e Kaneko et al. (2010) que não observaram influência da inoculação para os teores foliares de nitrogênio no feijoeiro e concordando com Souza et al. (2011) que verificaram maior teor de $\mathrm{N}$ na folha do feijoeiro quando inoculado com rizóbio. A presença de $\mathrm{N}$ no solo pode interferir na produtividade de grãos, no qual baixos teores de $\mathrm{N}$ no solo podem promover a senescência das folhas mais velhas e consequentemente o decaimento na taxa fotossintética em decorrência a translocação de $\mathrm{N}$ das folhas para os grãos, diminuindo assim a taxa fotossintética para as folhas remanescentes ocasionando em menor produtividade de grãos (PORTES, 1996). De toda forma, os teores foliares de $\mathrm{N}$ encontrados em todos os tratamentos ficaram acima da faixa considerada adequada para a cultura. De acordo com Ambrosano et al. (1996), os valores adequados para faixa de teores de $\mathrm{N}$ foliar no feijoeiro ficam entre 3 a $5 \%$.

Com relação ao teor de $\mathrm{N}$ nos grãos, os teores variaram entre 3,9 a $5,3 \%$, que são 
considerados adequados (Tabela 4) e apresentaram o mesmo comportamento observado para o $\mathrm{N}$ foliar. Com a inoculação a maior produtividade de grãos foi obtida com 20 $\mathrm{kg} \mathrm{ha}^{-1} \mathrm{~N}$ em semeadura, mas não diferiu da ausência de aplicação de $\mathrm{N}$ e da dose de $120 \mathrm{~kg}$ $\mathrm{ha}^{-1} \mathrm{~N}$ em cobertura. Para o feijão não inoculado, na ausência de $\mathrm{N}$ obteve-se a maior produtividade de grãos, embora não tenha diferido da dose de $20 \mathrm{~kg} \mathrm{ha}^{-1} \mathrm{~N}$ na semeadura (Tabela 4), podendo indicar alta competitividade dos rizóbios nativos do solo. Romanini Júnior et al. (2007) obtiveram respostas significativas na inoculação com bactérias fixadoras de $\mathrm{N}$, enquanto Barros et al. (2013) encontraram maior produtividade de grãos em tratamento adubado e inoculado, ressaltando que a inoculação pode substituir a dose de $20 \mathrm{~kg}$ de ha ${ }^{-1} \mathrm{~N}$ em plantio não inoculado, mantendo a mesma produtividade.

\section{CONCLUSÕES}

A aplicação de $\mathrm{N}$ afeta a produção e a massa seca de nódulos nas cultivares do feijoeiro Jalo precoce e Majestoso. A inoculação propicia maiores teores de $\mathrm{N}$ foliar e de grãos para $\mathrm{o}$ feijão Jalo precoce. A aplicação de $\mathrm{N}$ em semeadura e ou em cobertura resulta em maiores teores de $\mathrm{N}$ foliar e de grãos para $\mathrm{O}$ feijão Majestoso. Obtêm-se as maiores produtividades de grãos para o feijão Jalo precoce nas maiores doses de $\mathrm{N}$ sem inoculação e com $20 \mathrm{~kg} \mathrm{ha}^{-1} \mathrm{~N}$ na semeadura quando inoculado.

\section{REFERÊNCIAS}

AMBROSANO, E.J.; TANAKA, R.T.; MASCARENHAS, H.A.A.; RAIJ, B. van; QUAGGIO, J.A.; CANTARELLA, H. Leguminosas e oleaginosas. In: RAIJ, B. van; CANTARELLA, H.; QUAGGIO, J.A.; FURLANI, A.M.C. (Ed.). Recomendações de adubação e calagem para o Estado de São Paulo. 2.ed. Campinas: Instituto Agronômico, 1996. p.189-203.

ARAÚJO, F. F. DE; CARMONA, F. G.; TIRITAN, C. S.; CRESTE, J. E. Fixação biológica de $\mathrm{N}_{2}$ no feijoeiro submetido a dosagens de inoculante $e$ tratamento químico na semente comparado à adubação nitrogenada. Acta Scientiarum Agronomy, v.29, n.4, p.535-540, 2007. https://doi.org/10.4025/actasciagron.v29i4.416

BARROS, R. L. N.; DE OLIVEIRA, L. B.; DE MAGALHÃES, W. B.; MÉDICl, L. O.; PIMENTEL, C.
Interação entre inoculação com rizóbio e adubação nitrogenada de plantio na produtividade do feijoeiro nas épocas da seca e das águas. Semina: Ciências Agrárias, v.34, n.4, p.1443-1450, 2013. https://doi: 10.5433/1679$\underline{0359.2013 v 34 n 4 p 1443}$

CARDOSO, E. J. B. N.; ANDREOTE, F. D. Microbiologia do Solo. 2.ed. Piracicaba, ESALQ, 2016. 221 p. https://doi.org/10.11606/9788586481567

CONAB. COMPANHIA NACIONAL DE ABASTECIMENTO. Feijão: análise janeiro 2018. Brasília: Companhia Nacional de Abastecimento. 2018.

DA SILVA E. F.; MARCHETTI, M. E.; DE SOUZA, L. C. F.; MERCANTE, F. M.; RODRIGUES, E. T.; VITORINO, A. C. T. Inoculação do feijoeiro com Rhizobium tropici associada à exsudato de Mimosa flocculosa com diferentes doses de nitrogênio. Bragantia, v.68, n.2, p.443-451, 2009. http://dx.doi.org/10.1590/S0006$\underline{87052009000200019}$

FIGUEIREDO M. A. Inoculação com Rhizobium spp. e adubações nitrogenada e molibdica no feijoeiro-comum. 2012. 100p. Dissertação (Mestrado em Produção Vegetal) - UFLA.

FONSECA, G. G.; OLIVEIRA, D. P.; SOARES, B. L.; FERREIRA, P. A. A.; TEIXEIRA, C. M.; MARTINS, F. A. D.; MOREIRA, F. M. DE S.; DE ANDRADE, M. J. B. Resposta de cultivares de feijoeiro-comum à inoculação das sementes com duas estirpes de rizóbio. Bioscience Journal, v.29, n6.6, p.17781787, 2013.

GALVANI, F.; GAERTNER, E. Adequação da metodologia Kjeldahl para determinação do nitrogênio total e proteína bruta. Corumbá: Embrapa, 9p. 2006.

GRANGE, L.; HUNGRIA, M.; GRAHAM, P. H.; MARTíNEZ-ROMERO, E. New insights into the origins and evolution of rhizobium that nodulate common bean (Phaseolus vulgaris) in Brazil. Soil Biology \& Biochemistry, v.39, n.4, p.867-876, 2007.

https://doi.org/10.1016/j.soilbio.2006.10.008

GOMES JUNIOR, F.G.; LIMA, E.R.; LEAL, A.J.F.; MATOS, F.A.; SÁ, M.E.de; HAGA, K.I. Teor de proteína em grãos de feijão em diferentes épocas 
e doses de cobertura nitrogenada. Acta Scientiarum, v.27, n.3, p.455-459, 2005.

GOMES JUNIOR, F. G.; DE SÁ, M. E. Proteína e qualidade de sementes de feijão (Phaseolus vulgaris $L$.) em função da adubação nitrogenada em plantio direto. Revista Brasileira de Sementes, v. 32, n. 1., p. 034-044, 2010.

HUNGRIA, M.; CAMPO, R. J.; MENDES, I. A importância do processo de fixação biológica do nitrogênio para a cultura de soja: Componente essencial para a competitividade do produto brasileiro. Londrina, 80p. 2007.

HUNGRIA, M.; CAMPO, R. J.; MENDES, I. C. Benefits of inoculation of the common bean (Phaseolus vulgaris) crop with efficient and competitive Rhizobium tropici strains. Biology and Fertility of Soils, v.39, n.2, p.88-93, 2003. https://doi.org/10.1007/s00374-003-0682-6

HUNGRIA, M.; CAMPO, R. J.; MENDES, I. C. Fixação biológica do nitrogênio na cultura da soja. Londrina, 48p. 2001.

KANEKO, F. H.; ARF, O.; GITTI, D. DE C.; ARF, M. V.; FERREIRA, J. P.; BUZETTI, S. Mecanismos de abertura de sulcos, inoculação e adubação nitrogenada em feijoeiro em sistema plantio direto. Bragantia, v.69, n.1, p.125-133, 2010. https://doi.org/10.1590/S0006$\underline{87052010000100017}$

MARSCHNER, $H$. Mineral nutrition of higher plant. 2.ed. New York: Academic Press, 1995. 889p.

MERCANTE, F. M.; OTSUBO, A. A.; LAMAS, F. M. Inoculação de Rhizobium tropici e aplicação de adubo nitrogenado na cultura do feijoeiro, Bonito, MS, In: Reunião brasileira de fertilidade de solo e nutrição de plantas; reunião brasileira sobre micorrizas; simpósio brasileiro de microbiologia do solo; reunião brasileira de biologia do solo. Resumos... Dourados: Embrapa Agropecuária Oeste. 27p. 2006.

PELEGRIN, R. de; MERCANTE, F. M.; OTSUBO, I. M. N.; OTSUBO, A. A. Resposta da cultura do feijoeiro à adubação nitrogenada e à inoculação com rizóbio. Revista Brasileira de Ciência do Solo, v.33, n.1, p.219-226, 2009. https://doi.org/10.1590/s0100$\underline{06832009000100023}$
PORTES, T. A. Ecofisiologia. In: ARAÚJO, R.S.; RAVA, C.A.; STONE, L.F.; ZIMMERMANN, M.J.O. Cultura do feijoeiro comum no Brasil. Piracicaba, Potafós, 1996. p.101-137.

RICHETTI A, M. C. L. P.; SOUZA, J. P. B. Viabilidade Econômica da Cultura do Feijão Comum, Safra 2012, em Mato Grosso do Sul. Dourados: Embrapa Agropecuária Oeste. 9p. 2011.

ROMANINI JÚNIOR, A.; ARF, O.; BINOTTI, F. F. DA S.; DE SÁ, M. E.; BUZETTI, S.; FERNANDE, F. A. Avaliação da inoculação de rizóbio e adubação nitrogenada no desenvolvimento do feijoeiro, sob sistema plantio direto. Bioscience Journal, v.23, n.4, p.74-82, 2007.

SOUZA, E. F. C.; SORATTO, R. P.; PAGANI, F. A. Aplicação de nitrogênio e inoculação com rizóbio em feijoeiro cultivado após milho consorciado com braquiária. Pesquisa Agropecuária Brasileira, v.46, n.4, p.370-377, 2011. https://doi.org/10.1590/S0100-

$\underline{204 \times 2011000400005}$

SOUSA, D. M. G. DE; LOBATO, E. Cerrado: correção do solo e adubação. 2. ed. Brasília: Embrapa Informação Tecnológica, 2004. 416 p.

STRALIOTTO, R. A importância da inoculação com rizóbio na cultura do feijoeiro. Seropédica: Embrapa Agrobiologia/CNPAB. 6p. 2002.

TAIZ, L.; ZEIGER, E.; MØLLER, I. M.; MURPHY, S. Fisiologia e desenvolvimento vegetal. 6.ed. Porto Alegre, 2017. 888 p.

VIEIRA, R. F.; TSAI, S. M.; TEIXEIRA, M. A. Nodulação e fixação simbiótica de nitrogênio em feijoeiro com estirpes nativas de rizóbio, em solo tratado com lodo de esgoto. Pesquisa Agropecuária Brasileira, v.40, n.10, p.1047-1050, $2005 . \quad$ https://doi.org/10.1590/S0100$\underline{204 \times 2005001000015}$

Recebido para publicação em 16/01/2018

Revisado em 02/04/2018

Aceito em 10/04/2018 